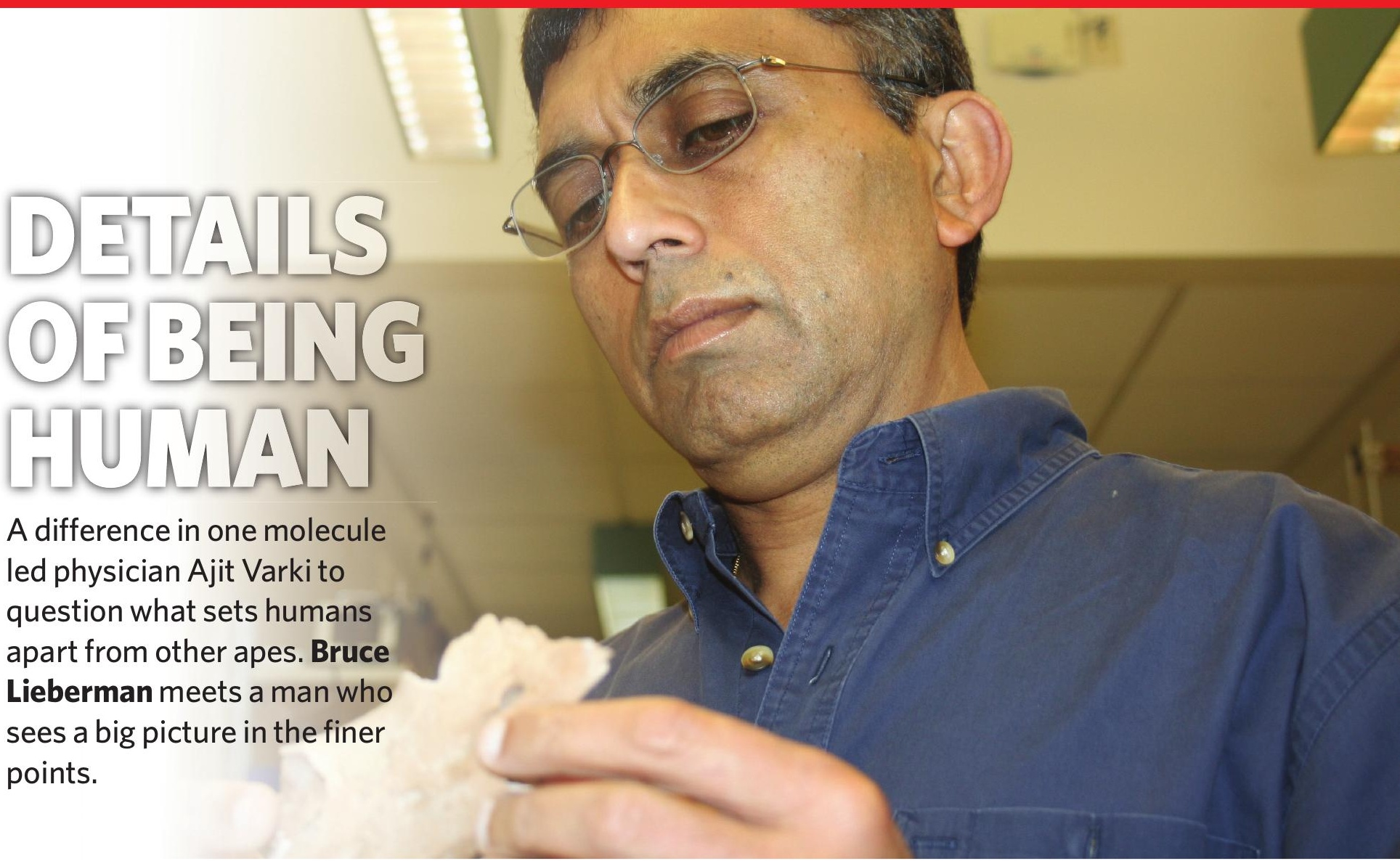

T he human body does not welcome an injection of horse serum. Ajit Varki discovered this when, as a young San Diego doctor in 1984, he administered some to a woman with bone-marrow failure. The serum was a standard treatment intended to stop the woman's $\mathrm{T}$ cells from destroying her bone marrow. But it was also known to prompt a reaction called 'serum sickness' and, sure enough, the patient broke out in hives a week after treatment - the result, Varki assumed, of her immune system's assault on proteins from another species.

Soon after observing his patient's reaction, Varki learned that proteins weren't the only thing to blame. So were sialic acids, sugars that carpet the surface of mammalian cells. Some studies had suggested that the human immune system reacted against one sialic acid called $N$-glycolyl neuraminic acid (Neu5Gc) in the horse serum. "How can that be?" Varki remembers thinking. "How can you have a reaction against sialic acid? It's everywhere. All mammals have sialic acid." Varki wondered whether humans might in fact be the only mammal that lacked Neu5Gc.

A physician and biochemist by training, Varki had already embarked on a career in the relatively new field of glycobiology, the study of the sugar chains that decorate many proteins and lipids inside and outside the cell. But it was another 14 years before he got the chance to answer his original question. In 1998, he and his colleagues used high-performance liquid chromatography to analyse blood samples from chimps, bonobos, gorillas, orangutans and humans. They found that humans are indeed the only primates missing Neu5 $\mathrm{Gc}^{1}$ and that human cells are instead rich in another sialic acid, $\mathrm{N}$-acetyl neuraminic acid (Neu5Ac).

\section{A career in evolution}

These findings started Varki off on a road that led to his becoming not only a leading glycobiologist but a respected 'honorary' palaeoanthropologist. He is one of the co-founders and directors of the multidisciplinary Center for Academic Research and Training in Anthropogeny (CARTA) - a research collaboration between the University of California, San Diego, and the Salk Institute in nearby La Jolla. The centre was launched in March this year with a US\$3-million grant from the G. Harold \& Leila Y. Mathers Foundation,
"What we're dealing with here is a gene loss that has an effect throughout the whole body." - Morris Goodman
Homo antecessor fossils from Atapuerca in northern Spain, some of the oldest hominid bones yet found in Europe. What Varki is looking for is evidence that Neu5Gc was lost very ${ }^{\infty}$ early in human evolution. He believes that the fact that humans, and only humans, have lost Neu5Gc could be implicated in the emergence of hominid species.

The journey from glycobiologist to director of a multidisciplinary human origins centre has been fuelled by Varki's insatiable desire for knowledge. "The guy is just an encyclopaedia," says glycobiologist Mark Lehrman at the University of Texas Southwestern Medical Center in Dallas. "Even though he wasn't trained in anthropology, he's been able to educate himself in this area and become an authority. It's a remarkable gift to be able to do that and do it well."

Varki initially trained as a general medical doctor at the

The 'Anthropogeny' in the centre's title resurrects a term for the study of both the evolution and the individual development of human beings that would have been familiar to earlier generations of anthropologists. To Varki, the word encapsulates some of the biggest questions in the study of human origins, such as how, why and when the human brain evolved its present functions. One of his latest research projects is a collaboration with Spanish palaeontologist Juan Luis Arsuaga, of the Complutense University of Madrid, for the biochemical analysis of 900,000-year-old
Christian Medical College in Vellore, India. To pursue a dual medical and research career, he went to the United States, eventually taking up a fellowship under Stuart Kornfeld at Washington University in St Louis, Missouri, in the late 1970s.

Kornfeld was beginning his work on sugar chains, including sialic acids, and Varki was intrigued by the opportunity to contribute to a largely unexplored area of biology. In 1982, he set up his own glycobiology lab at the University of California, San Diego, where he still works today. 


\section{SMALL CHANGE, BIG DIFFERENCE}

A mutation during human evolution means that humans accumulate the sialic acid Neu5Ac whereas other primates also make Neu5Gc
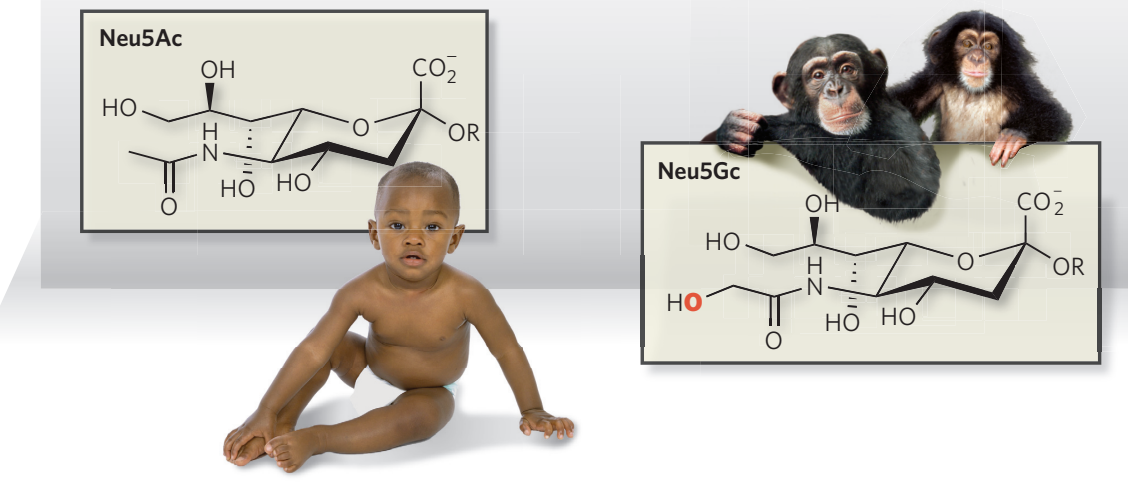

On a molecular level, the difference between Neu5Gc and Neu5Ac is tiny - a single added oxygen atom perched on one arm distinguishes one from the other (see graphic). But on a biological level, the difference could be enormous. "We thought if monkeys and all of our closest relatives have Neu5Gc and humans don't, then there must be a molecular basis for that," Varki says. He subsequently found it in an enzyme that converts Neu5Ac to Neu5Gc, but which is disabled by mutation in humans ${ }^{2}$.

\section{Selection pressure}

Varki's discovery pointed to a definitive difference that set chimps and humans biochemically apart, says Morris Goodman, an evolutionary biologist at Wayne State University in Detroit, Michigan. It was one of the first such differences to be found, and because sialic acids serve many biological roles, primarily as cell-recognition and cell-adhesion molecules, it might explain some of the unique aspects of human biology. "What we're dealing with here is a gene loss that has an effect throughout the whole body," says Goodman.

At the time, Varki realized he knew little about

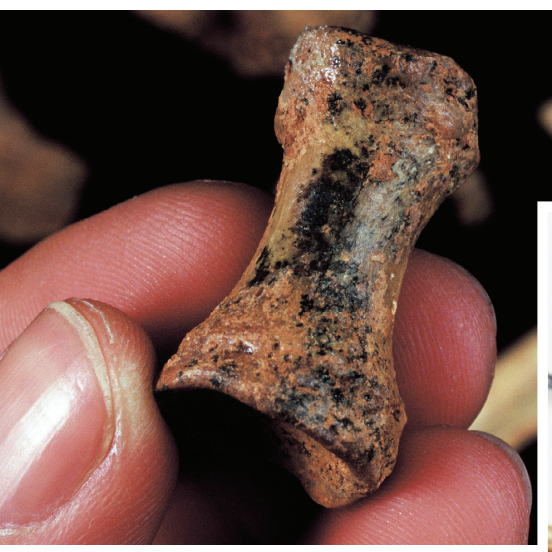

Tests of Homo antecessor fossils could help confirm the loss of Neu5Gc early in human evolution. human evolution except what he'd learned as an undergraduate or read in National Geographic. So he set out to educate himself. He took a short sabbatical at the Yerkes National Primate Research Center in Atlanta, Georgia. Reviewing the animals' medical records with a veterinarian, he learned that the centre had never seen a case of rheumatoid arthritis or bronchial asthma - common conditions in humans. Chimpanzees don't get sick from the human malaria parasite, Plasmodium falciparum. Conversely, humans can't be infected with $P$. reichenowi, the malaria parasite that plagues chimpanzees.

In subsequent work, Varki and his team showed that the different susceptibilities were due to the differences in sialic acids. P. reichenowi prefers to grab hold of Neu5Gc on chimp red blood cells, whereas $P$. falciparum favours $\mathrm{Neu} 5 \mathrm{Ac}^{3}$. The researchers hypothesized that the selection pressure to evade $P$. reichenowi may have led humans to lose Neu5Gc and acquire resistance to this parasite - and that this loss may have helped to fuel the emergence of $P$. falciparum, which could gain entry by latching onto Neu5Ac instead. Other discoveries in Varki's lab - including ten other human-specific genetic changes affecting sialic acid function - may help to explain uniquely human vulnerabilities to conditions such as Alzheimer's disease and multiple sclerosis.

Varki's interest in human evolution soon extended far beyond chimps and their sugars. "I found he was talking with several people on campus," says neuroscientist Fred Gage at the Salk Institute, a long-time collaborator and friend. "I told him that it wasn't fair that

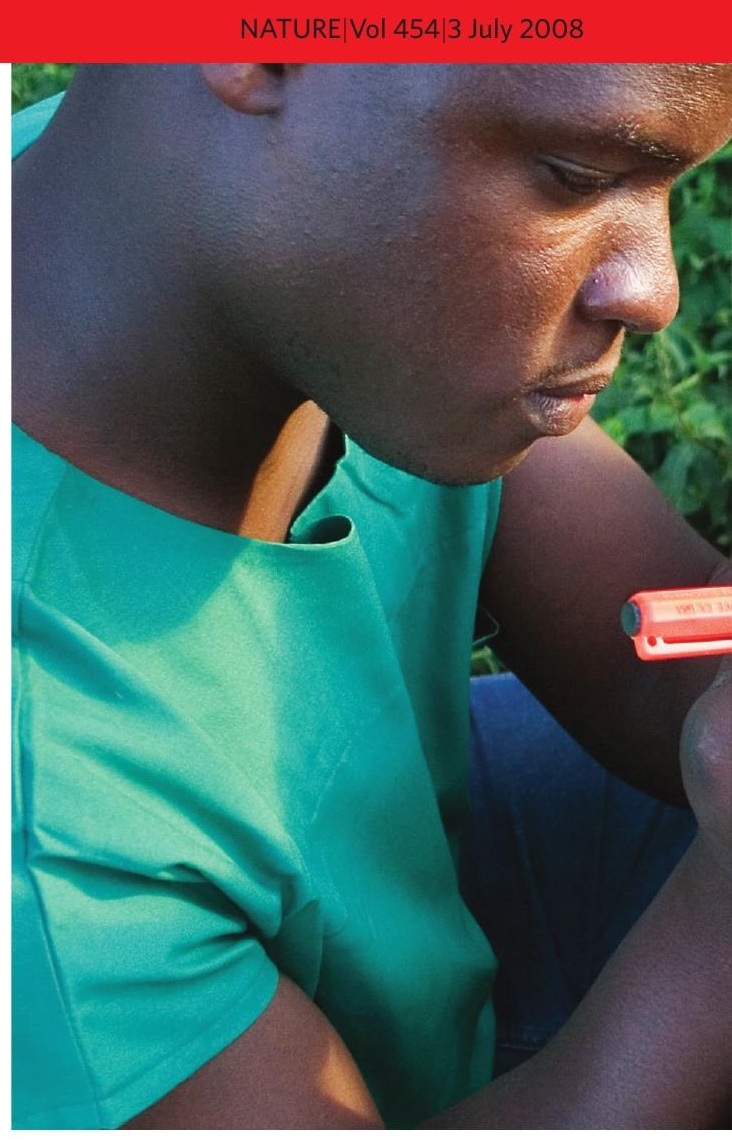

he would have these one-on-one conversations and not share what was being talked about," he jokes.

\section{Reimagining anthropogeny}

Gage encouraged Varki to organize a series of informal seminars on human origins at the university. Between 1998 and 2007, the Project for Explaining the Origin of Humans drew in anthropologists, primate biologists, geneticists, immunologists, neuroscientists, linguists and many others. They discussed topics ranging from the evolution of language to the differences between humans, Neanderthals and Homo erectus, the first hominid to leave Africa. Goodman says the interdisciplinary nature of the series made it extremely important to the field. "You really had the chance to explore an issue as it relates to the evolutionary origins of our species," he says.

Varki's motivations were partly selfish: "One of my goals, my secret agenda, was to educate myself," he admits. "At the last meeting I asked the people who attended if I could have a bachelor's degree in anthropogeny." Varki estimates that he has listened to more than 300 talks on various aspects of this discipline. "The idea is the linguist needs to talk to the molecular biologist who needs to talk to the neuroscientist who needs to talk to the psychologist and philosopher about these issues," he says. "Most areas of human knowledge are somewhere relevant."

CARTA is a successor to the human origins series. Directed by Varki, Gage, Margaret Schoeninger, a professor of anthropology at the University of California, San Diego, and Pascal Gagneux, a primate biologist and Varki's close collaborator, the centre already has some 40 


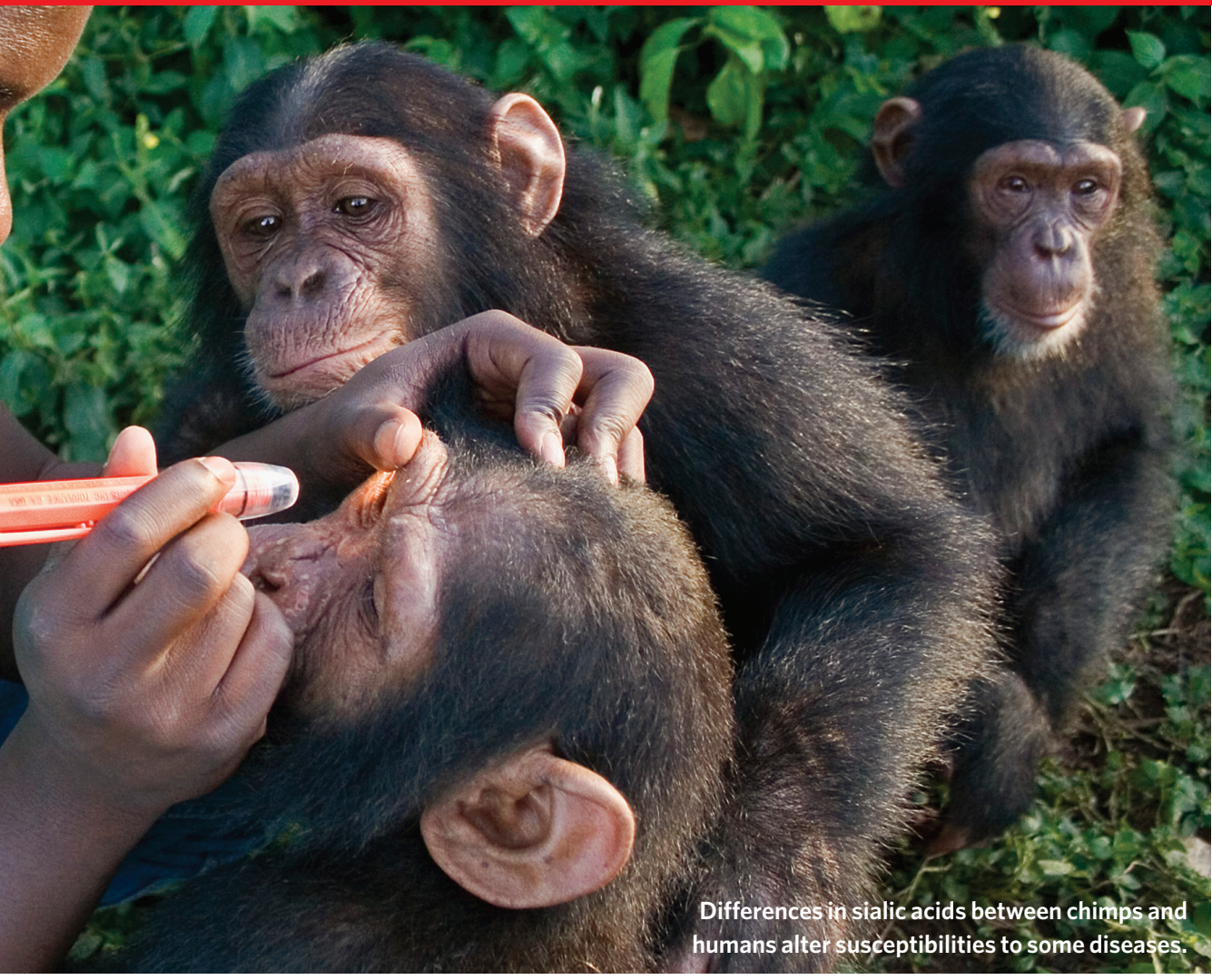

San Diego-based members and more than 100 in the rest of the United States and elsewhere in the world.

CARTA aims to foster connections between these researchers worldwide, facilitate access to resources for great-ape research, develop a peer-reviewed journal and offer courses on human origins. The project is in some ways comparable to the Leipzig School of Human Origins in Germany, an interdisciplinary $\mathrm{PhD}$ programme run jointly by the Max Planck Institute for Evolutionary Anthropology in Leipzig and Leipzig University since 2005. Varki says that CARTA will be more of a virtual organization and that "the effort should transcend disciplines", pointing as an example to his own work on sialic acids, which has required collaboration between biochemists, palaeontologists and physicians.

\section{Acid test}

Back in the lab, Varki and Gagneux will in the next few months embark on the preliminary analysis of animal fossils from Atapuerca, to see if they can detect preserved sialic acids using high-performance liquid chromatography and mass spectrometry. If so, sialic acids are likely to be preserved in hominid fossils from the same strata and the researchers will test those next.

"Palaeontologists are usually seen as people interested in something that is finished and belongs to the past," Arsuaga says, "and usually the idea is missed that we are looking for an explanation of living humans." He says he was persuaded to let tests be done on the precious $H$. antecessor fossils because "the damage is not big" from current techniques that drill small amounts of powder from inside the bone.

Varki and Gagneux hope that these fossils may help to answer some grand hypotheses about Neu5Gc and its role in human evolution. They estimate that the mutation that caused the loss of Neu5Gc first appeared among human ancestors 2 million to 3 million years ago, which coincides with the emergence of $H$. erectus, and they believe that pathogens such as malaria may have initiated this change. They wonder whether the change in this ubiquitous sugar could have had other broad-ranging biological effects that helped create reproductive isolation between those with Neu5Gc and those without, and whether these effects could have contributed to the emergence of $H$. erectus, followed by $H$. antecessor. "Losing Neu5Gc may have been

"Understanding where we came from is very important to understanding where we're going." - Ajit Varki great for survival, but it may have forced you to forgo reproduction with a whole group of your former buddies who didn't undergo this change," Gagneux says. If they can show that Arsuaga's $H$. antecessor fossils also lack Neu5Gc, this will be yet more evidence in support of their hypothesis.

If ancient humans can't answer the speciation hypothesis, then perhaps mice will help. Varki and Gagneux have genetically engineered mice that lack the Neu5Gc sialic acid that humans are missing and Varki says that they display subtle human-like features ${ }^{4}$. Compared with wild-type mice, they have poor hearing, somewhat reminiscent of human age-related hearing loss, and slower wound healing, as do humans compared with nonhuman primates. Further studies should reveal whether these mice are able to reproduce with (1998). (1998) wild-type animals that still have Neu5Gc.

Varki's recent work has brought him back to the immune reaction he observed nearly 25 years ago. Even though humans don't make $\mathrm{Neu} 5 \mathrm{Gc}$, it is eaten in animal products that contain it, such as meat and milk. Varki and Gagneux wonder whether - among meateaters at least - Neu5Gc elicits an immune reaction that might contribute to a whole spectrum of human-specific diseases that are associated with chronic inflammation, including heart disease and cancer. Such diseases would not have been such a problem when humans had shorter life spans.

\section{Food for thought}

To test the idea, Gagneux took a trip to a local Whole Foods Market, loaded up a shopping cart with meat and dairy products and took them back to the lab for analysis. The researchers found the highest levels of Neu5Gc in lamb, pork and beef. "We swallowed big bowls of that and we collected every possible sample we could from ourselves in the following few weeks to see whether it shows up in our own glycoproteins," Gagneux says, "and the answer is yes, it does." The team has also found that many people carry antibodies targeted against the sugar ${ }^{5}$.

If their hypothesis holds up, it will illustrate how selection pressures change: where once selection favoured the loss of Neu5Gc to protect hominids from pathogens, now its absence could be making humans susceptible to other diseases. "Once you've lost it, you have to make do with what you have," Varki says.

For Varki, who began his professional life observing patients, these studies have brought him full circle. The molecules that made humans human may be the same ones that make us uniquely vulnerable to our most threatening diseases. "In some cases, they would be what I call the scars of our evolution," Varki says. "My experience has opened my mind to the fact that understanding human evolution, where we came from, is very important to understanding who we are and where we're going."

Bruce Lieberman is a freelance science writer based in San Diego.

1. Muchmore, E. A. et al. Am. J. Phys. Anthropol. 107, 187-198

2. Chou, H.-H. et al. Proc. Natl Acad. Sci. USA 95, 11751-11756

3. Martin, M. J. et al. Proc. Natl Acad. Sci. USA 102, 12819 12824 (2005)

4. Hedlund, M. et al. Mol. Cell. Biol. 27, 4340-4346 (2007)

5. Tangvoranuntakul, P. et al. Proc. Natl Acad. Sci. USA 100, 12045-12050 (2003) 